\title{
ENTRE LAS REDES Y LAS CALLES: ORGANIZACIONES Y ACCIONES COLECTIVAS JUVENILES DURANTE LA PANDEMIA (2020- 2021)
}

\author{
MELINA VÁZQUEZ ${ }^{1}$ \\ ALEJANDRO COZACHCOW ${ }^{2}$
}

\begin{abstract}
RESUMEN
El artículo analiza el activismo político de las y los jóvenes durante la pandemia por la Covid-19 en la Argentina a partir de un relevamiento de organizaciones y acciones colectivas juveniles realizado entre 2020 y 2021. El trabajo aborda tres dimensiones: a) las maneras de tramitar las relaciones entre presencialidad y virtualidad en los repertorios de acción colectiva, así como en la organización interna de los grupos; b) las reconfiguraciones y temas emergentes en las agendas y causas militantes; c) la movilización en las calles durante la pandemia y la revitalización de grupos de derecha que interpelan a las juventudes.
\end{abstract}

PALABRAS ClAVES: JÓVENES, ACTIVISMOS, COVID-19.

\footnotetext{
${ }^{1}$ Posdoctora en investigación en infancias y juventudes (CLACSO), Doctora y Magíster en Ciencias Sociales, Universidad de Buenos Aires (UBA). Investigadora Adjunta del Consejo Nacional de Investigaciones Científicas y Técnicas con sede en el Instituto de Investigaciones Gino Germani (FSOC-UBA), donde co-coordina el Grupo de Estudios en Políticas y Juventudes (IIGG-UBA). Profesora de la carrera de Sociología de la UBA y co-coordinadora del GT Infancias y Juventudes de CLACSO. Correo electrónico:mvazquez@sociales.uba.ar

2 Doctor en Ciencias Sociales, Universidad de Buenos Aires (UBA). Magíster en Ciencias Sociales (UNGS-IDES). Becario Posdoctoral del Consejo Nacional de Investigaciones Científicas y Técnicas con sede en el Instituto de Investigaciones Gino Germani (FSOC-UBA). Miembro del Grupo de Estudios en Políticas y Juventudes (IIGG-UBA). Docente de la carrera de Sociología de la UBA y miembro del GT Infancias y Juventudes de CLACSO. Correo electrónico: alecoza@sociales.uba.ar
} 


\title{
ENTRE AS REDES E AS RUAS: ORGANIZAÇÕES JUVENIS E AÇÕES COLETIVAS DURANTE A PANDEMIA (2020-2021)
}

\begin{abstract}
RESUMO
Este artigo analisa o ativismo político dos e das jovens durante a pandemia de Covid-19 na Argentina, com base em um levantamento de organizações e ações coletivas juvenis realizado entre 2020 e 2021. O trabalho aborda três dimensões: a) as formas de processar as relações entre presencialidade e virtualidade nos repertórios de ação coletiva, assim como na organização interna dos grupos; b) as reconfigurações e questões emergentes nas agendas e causas militantes; c) a mobilização nas ruas durante a pandemia e a revitalização de grupos de direita que desafiam as juventudes.
\end{abstract}

PALAVRAS-CHAVE: JOVENS, ATIVISMOS, COVID-19.

\section{BETWEEN THE NETWORKS AND THE STREETS: YOUTH ORGANIZATIONS AND COLLECTIVE ACTIONS DURING THE PANDEMIC (2020-2021)}

\begin{abstract}
The article analyzes the political activism of young men and women during the COVID19 pandemic in Argentina based on a survey about youth collective actions and organizations carried out between 2020 and 2021. The work covers three dimensions: a) the ways of processing the relations between presentiality and virtuality in the repertoires of collective action, as well as in the internal organization of the groups; b) the reconfigurations and emerging matters in the activists causes and agendas; c) the mobilization in the streets during the pandemic and the revitalization of right-wing groups questioning youths.
\end{abstract}

KEYWORDS: YOUNG PEOPLE, ACTIVISMS, COVID-19. 


\section{INTRODUCCIÓN Y ESTADO DE LA CUESTIÓN}

La coyuntura producida a partir de la caracterización del Covid-19 como pandemia por parte de la Organización Mundial de la Salud a comienzos de marzo de 2020 produjo heterogéneas intervenciones por parte de los Estados Nacionales. En cada caso, se adoptaron medidas económicas, sociales, educativas, laborales e, incluso, recreativas. La restricción de la circulación formó parte de las estrategias desarrolladas por buena parte de los países para frenar la circulación del virus, limitando los contactos entre personas. Estados de sitio, toques de queda, límites a circular por las calles en determinados horarios o días fueron algunas de las medidas adoptadas. A medida que transcurrió el tiempo, dichas medidas se relajaron o endurecieron de acuerdo con la situación sanitaria y el margen de maniobra de los gobiernos en función del hartazgo social.

Según Filleule (2020), durante los inicios de la pandemia se dieron debates en torno a los efectos de esta crisis desde el punto de vista sanitario, económico y social; sin embargo, dimensiones como la pérdida del espacio público en tanto escenario de la movilización social no habían sido suficientemente abordados. Desde la publicación de dicho trabajo identificamos algunas investigaciones internacionales sobre las estrategias de movilización social y política en diferentes países y regiones (Della Porta, 2020; Pleyers, 2020; Milan, Treré y Masiero, 2021). Para el caso argentino, se hicieron relevamientos de acciones visibles de protestas, en general (Ciuffolini et al., 2020; Soto Pimentel et al., 2021), o centrados en el estudio de grupos particulares, como los que analizan la conflictividad laboral y la movilización de trabajadores (Natalucci et al., 2020; Nava y Grigera, 2020; Basualdo y Peláez, 2020). El estudio de las juventudes movilizadas ha sido objeto de menor atención, aunque se han realizado algunas publicaciones (Vázquez y Cozachcow, 2020; Morresi, Vicente y Saferstein, 2020). 
Las producciones mencionadas realizan valiosos aportes a la comprensión de las acciones colectivas contenciosas y asumen el desafío de hacerlo cuando los hechos están teniendo lugar. Sin embargo, aquellas que colocan el foco del análisis en las protestas y formas visibles de movilización dejan en las sombras aspectos relativos a los impactos de la pandemia en las tramas organizativas de los grupos, así como también en la construcción de agendas de trabajo, ya sea cotidiano o en el marco de las acciones visibles de las que forman parte. Asimismo, por los límites que posee la investigación en una coyuntura tan fluctuante, estos trabajos tampoco alcanzan a dar cuenta del carácter dinámico de las acciones colectivas, al centrarse en períodos muy cortos de tiempo.

Los estudios sobre las juventudes en la pandemia abordaron temas como los vínculos entre desigualdades (Chaves, 2021; Vommaro, 2020) y trabajo (Haidar, 2020; López Mourelo, 2020); los efectos de virtualización de la educación (Núñez y Gurvich, 2021; Ziegler, 2021; UNICEF, 2021), y la producción de discursos estigmatizantes que les atribuyen responsabilidad frente al aumento de los contagios (GEPOJU, 2021).

En este artículo recuperamos los aportes de los campos de la acción colectiva y las juventudes para explorar los efectos en la movilización juvenil durante la pandemia. Con respecto al primero, retomamos los aportes de la sociología del compromiso político (Agrikolianski, 2001; Pudal, 2011; Filleule, 2015; Sawicki y Siméant, 2009) para el análisis de las formas de activismo, así como de las reconfiguraciones en las formas de acción colectiva y de protesta social en el espacio público (Fillieule y Tartakowsky, 2015; Filleule, 2020). Con respecto al segundo, adoptamos una perspectiva sociopolítica orientada a la comprensión de la juventud en tanto que categoría público-política que define los compromisos y las causas militantes (Vázquez, 2015). Recuperamos, además, los aportes de las miradas socioantropológicas que analizan los impactos de las culturas digitales en el desarrollo de activismos juveniles (Feixa, 2014; Reguillo, 
2017). Nos interesa analizar los repertorios de acción considerando las relaciones entre presencialidad y virtualidad, tanto en lo referido a las dinámicas movilizatorias como en las estrategias organizativas adoptadas durante la pandemia. Además, indagamos el impacto de la misma en la construcción de agendas y causas militantes en los grupos. Por último, identificamos elementos emergentes de las formas de movilización juvenil, en especial, la revitalización de las llamadas «nuevas derechas» que, como proponemos, encuentran en las medidas de aislamiento y restricción de la circulación un contexto de oportunidad política para visibilizar grupos y agendas. Las medidas de aislamiento propician la participación de estos sectores en las calles con un discurso antigobierno que sostiene una estética de la movilización y la resistencia que busca disputar la representación política de las juventudes.

El trabajo forma parte de una investigación colectiva más amplia realizada desde el Grupo de Trabajo de infancias y juventudes de CLACSO (Vázquez et al., 2021) orientada a estudiar los efectos de la pandemia en las acciones colectivas juveniles. La investigación consistió, centralmente, en la realización de una encuesta que se aplicó entre diciembre de 2020 y febrero de 2021 con referentes jóvenes de 165 organizaciones de Argentina, Brasil, Chile, Colombia, Ecuador, España y México. En este artículo recuperamos los resultados del trabajo de campo realizado para el caso argentino, en el que se incluyeron veintiocho grupos, entre los que incluimos colectivos partidarios, sindicales, ambientalistas, feministas, antiderechos, rurales y estudiantiles con diversos perfiles ideológicos. Dichos resultados se ponen en relación con un trabajo de campo cualitativo realizado por los autores que incluyó la realización de entrevistas en profundidad a activistas y el relevamiento y análisis de fuentes digitales, por medio de las cuales logramos reconstruir las formas de 
comunicación y las acciones realizadas durante la pandemia entre marzo de 2020 y febrero de $2021^{3}$.

En la primera parte del artículo se mencionan las medidas que reglamentaron el aislamiento y distanciamiento social en Argentina, incorporando al análisis la pregunta por el impacto de las mismas en el desarrollo de acciones colectivas contenciosas. Luego, se analizan las relaciones que sostienen los grupos entre acciones presenciales y virtuales, identificando algunas innovaciones vinculadas, por ejemplo, con la realización de caravanas de autos y de bicicletas. En tercer lugar, se analiza el modo en que el nuevo escenario impacta sobre las agendas y las causas militantes de los grupos. Por último, se abordan aspectos emergentes de la movilización en las calles, en especial, la participación de jóvenes en grupos que se identifican como parte de las derechas.

\section{ENTRE LAS RESTRICCIONES A LA CIRCULACIÓN Y LA MOVILIZACIÓN EN LAS CALLES}

En marzo de 2020 se decretaron en Argentina las primeras medidas vinculadas con la pandemia. La normativa estableció dos fases de cuarentena ${ }^{4}$ : Aislamiento Social Preventivo y Obligatorio (ASPO) y Distanciamiento Social Preventivo y Obligatorio (DISPO). La primera, más dura, involucra el confinamiento de la población en sus hogares. Solo permite los desplazamientos para obtener alimentos, artículos de limpieza o medicamentos, así como los de personas que realizan actividades «esenciales» en la emergencia (fuerzas de seguridad, médicos, asistencia en cuidados de otras personas, entre otros). La

\footnotetext{
${ }^{3}$ En el anexo se puede consultar la tabla de las organizaciones con las que trabajamos.

${ }^{4}$ DNU 297/2020.
} 
segunda, adoptada a partir de agosto $^{5}$ en zonas sin transmisión sostenida del virus, establece aperturas graduales de actividades y la circulación en transporte público. Respecto de la movilización en el espacio público, si bien la normativa decreta la prohibición de eventos de más de diez personas, en la Argentina, a diferencia de otros países, no se ha observado una prohibición explícita de las movilizaciones o la represión de las protestas con motivo de haber incumplido la normativa. Hasta aquí tiene lugar el período más estricto del aislamiento, aún cuando las situaciones entre distintas provincias - $\mathrm{O}$ al interior de una misma provincia- muestran variaciones.

En el mes de noviembre se establece el pasaje de ASPO a DISPO en el mayor aglomerado urbano del país: el Área Metropolitana de Buenos Aires. Entre febrero y marzo de 2021 las provincias planifican diversos esquemas de presencialidad para organizar el retorno a clases en los niveles inicial, primario y secundario que, sin embargo, coincide con el inicio de la segunda ola de casos, que lleva a nuevas restricciones.

En suma, el período que analizamos involucra una cuarentena con aislamiento duro con aperturas graduales de la actividad económica y de la circulación por el territorio nacional. Algunos estudios se preguntaron por los efectos de estas medidas en el desarrollo de las acciones de protesta social. Según Natalucci et al. (2020), entre el 16 de marzo y el 7 de junio, momento de mayor cierre de la circulación, tuvieron lugar un total de 489 protestas, esto representa un promedio de 6,1 protestas por día, mientras que entre los años 2011 y 2015 el promedio diario fue de 1,08. Por su parte, el trabajo de Soto Pimentel et al. (2020) muestra que las protestas son una constante del período: entre diciembre de 2019 y de 2020 relevan un total de 185 . Así, de acuerdo con ambos trabajos, se constata

\footnotetext{
${ }^{5}$ DNU 714/2020.
} 
la permanencia de la movilización en las calles, que crece cuando las medidas de restricción de la circulación se vuelven más laxas.

Diferentes actores políticos y sociales construyeron discursos públicos sobre la movilización. Los principales partidos que integran la oposición al gobierno de Alberto Fernández convocaron a diversas movilizaciones públicas durante la pandemia. Por su parte, el espacio político que encarna la representación del Poder Ejecutivo Nacional —Frente de Todos- adoptó distintas posturas en el tiempo. Al comienzo desalentó las movilizaciones ${ }^{6}$, luego promovió el uso de medidas de distancia social y barbijos. Además, impulsó la realización de actos políticos virtuales, transmitidos por medios audiovisuales de los que participan figuras con posiciones dirigenciales, como el realizado el 18 de diciembre de 2020 para celebrar el primer año de gestión de Axel Kiciloff, gobernador de la Provincia de Buenos Aires.

En la primera etapa de la pandemia, aproximadamente hasta el mes de octubre, tienen lugar acciones colectivas en las que prima una cierta idea de consenso y unidad que se plasma en una de las consignas elaboradas desde el oficialismo: «nadie se salva solo». En esa línea pueden interpretarse los aplausos a los médicos en los balcones, las campañas público-mediáticas con la consigna \#quedatencasa. Estas acciones colectivas articulan recursos online y offline que contribuyen a crear una «comunión activa» entre quienes se quedan en sus hogares por medio de la construcción del «nosotros», esto es, de quienes se perciben a sí mismos como parte de una lucha de la sociedad contra el virus (Fillieule, 2020). Sin embargo, como muestran estudios sobre otros países, la retórica de la unidad nacional para combatir al virus y la confianza en los gobiernos para llevar adelante la gestión de la crisis encuentra momentos de repliegue (Tassinari, Chesta y Cini, 2020).

\footnotetext{
${ }^{6}$ En esta línea pueden interpretarse las campañas que invitaron a virtualizar la tradicional marcha del 24 de marzo en conmemoración del último gobierno de facto en Argentina.
} 
A fines de 2020, durante la DISPO, tienen lugar diferentes acciones masivas en las calles que modifican los usos sociales de la movilización en las calles: los funerales del futbolista Diego Maradona; los debates en el Congreso Nacional del proyecto de ley para la legalización del aborto; el desarrollo de manifestaciones por parte de movimientos sociales (incluso algunos afines al gobierno) en los que se problematizan los efectos desiguales de la pandemia, así como también protestas con fuerte divulgación mediática de sectores opositores al gobierno y a las medidas de gestión de la crisis.

En tal sentido, las dinámicas cambiantes de la movilización pueden pensarse en relación con dos aspectos. Por un lado, de acuerdo con las normativas, que limitan o habilitan la circulación en las calles, y que afectan las dinámicas de la movilización. Vale señalar que en Argentina se sostuvo una política de tolerancia hacia las protestas sociales en las calles, en contraposición con otros países de Europa y América Latina, en los que fueron duramente reprimidas. Por otro lado, el propio curso de la pandemia produjo un contexto de oportunidad para el desarrollo de (nuevas) acciones colectivas contenciosas.

En suma, las medidas de aislamiento por la crisis sanitaria hicieron que grupos y movimientos ensayaran estrategias de adaptación al nuevo escenario. Para comprender dichas estrategias es importante reponer aspectos del contexto nacional o provincial y el momento del tiempo en el que tienen lugar.

\section{ENTRE LA PRESENCIALIDAD Y LA VIRTUALIDAD}

En esta sección analizamos el modo en que las organizaciones juveniles enfrentan el problema de la virtualidad en el escenario que se abre con la pandemia. Partimos de la hipótesis de que las restricciones a la circulación no explican, per se, la forma que adoptan las acciones colectivas, sino que es preciso comprender las adaptaciones y definiciones realizadas a partir de los 
conocimientos y saberes colectivos vinculados con el uso de formatos presenciales y virtuales dentro de los grupos; las lecturas que hacen sobre el contexto político general y las medidas gubernamentales en particular. Los efectos de la pandemia se analizan en dos facetas complementarias: en el desarrollo de acciones visibles como también en la implementación de estrategias de organización interna y en funcionamiento cotidiano de los grupos.

\subsection{FORMATOS Y REPERTORIOS DE ACCIÓN COLECTIVA JUVENIL EN PANDEMIA}

De acuerdo con los resultados de la encuesta a organizaciones juveniles

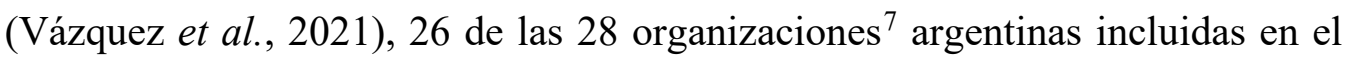
estudio realizaban acciones virtuales previo a la pandemia y siguieron haciéndolo durante la misma. En casi dos tercios (18/28) de los grupos sostienen que los formatos virtuales son menos eficaces que los presenciales y los valoran de forma positiva únicamente por las posibilidades que les dan durante la pandemia. En cinco organizaciones afirman que no hay grandes diferencias en el uso de los formatos presenciales y virtuales y solo tres consideran que no volverían a hacer uso de recursos virtuales cuando pase la pandemia. La Juventud de Propuesta Republicana (JPRO), partido de derecha fundado por el expresidente Mauricio Macri (2015-2019), es el único grupo que considera que los formatos virtuales son más valiosos que los presenciales para el desarrollo de sus acciones colectivas.

De acuerdo con el estudio, una cantidad significativa de organizaciones (20/28) realiza acciones colectivas presenciales en 2020. Entre estas, se registra

\footnotetext{
${ }^{7}$ La cantidad de organizaciones que integran la base es de 28. Por tal motivo, se presentan los resultados absolutos, no los porcentajes.
} 
una marcada heterogeneidad que va desde la realización de acciones solidarias hasta movilizaciones callejeras.

Es posible distinguir dos momentos. El primero, entre junio y octubre, en el que se mencionan cinco movilizaciones a favor y en contra del gobierno nacional; con reclamos ambientales o por los derechos contra las personas trans. El segundo da cuenta de un incremento de las acciones colectivas en el espacio público: casi las dos terceras partes (12) se realizan entre los meses de noviembre y diciembre, momento en el que se registra una disminución de la cantidad de contagios y en las restricciones a la circulación. Se destacan las movilizaciones a favor y en contra de la despenalización del aborto, finalmente aprobada por el Congreso Nacional. No obstante, la mayoría de los grupos (14/17) manifiesta haber utilizado distanciamiento social y medidas de cuidado para prevenir contagios en las movilizaciones.

Las acciones se realizaron en puntos neurálgicos de la Ciudad de Buenos Aires, donde históricamente se realizan las principales movilizaciones, como la Plaza de los Dos Congresos, y, en menor medida, en el Obelisco. Son menos los casos en los que se hacen acciones fuera de la Ciudad de Buenos Aires, como la movilización protagonizada por la Juventud del PRO frente al Aeropuerto de El Palomar en reclamo por su reapertura, o la Unión de Trabajadores de la Tierra en el Barrio San Carlos de La Plata, en el que tiene inserción esta organización.

Si analizamos las acciones colectivas de las que participan los colectivos antes y durante la pandemia notamos, en primer lugar, que todos los formatos de acción que utilizaban sufren alguna merma. Los que más disminuyen son las movilizaciones y protestas, la participación en paros y huelgas (que caen un 25\%, respectivamente) y la realización de intervenciones artísticas, que caen un $22 \%$. La realización de ocupaciones pasa del 14,8\% de las acciones antes de la pandemia a cero durante la misma. Otros formatos de acción sufren una caída 
pero menor, como las acciones de ayuda mutua y solidaridad; la comunicación masiva en redes y el impulso de acciones socioterritoriales.

En segundo lugar, los grupos innovan por medio de la realización de acciones que son, desde su punto de vista, «novedosas». No se trata de formatos de acción nuevos, sino que los grupos incorporan a sus repertorios en el nuevo escenario. La principal acción mencionada tiene que ver la participación en caravanas, de autos y en bicicletas. Estos formatos son utilizados por grupos tan heterogéneos como las juventudes sindicales (como la Asociación de Trabajadores del Estado y la Juventud Sindical), jóvenes de la Campaña Nacional por el derecho al aborto legal, seguro y gratuito, la Unión de Estudiantes Universitarios (UES), la Juventud del PRO y la agrupación Frente Joven, colectivo religioso que ha cobrado protagonismo en su intervenciones públicas en contra de la legalización del aborto y la educación sexual integral.

Pese a esta diversidad, es posible establecer una diferencia entre los usos de las caravanas de autos y los bicicletazos, respectivamente. Las primeras fueron utilizadas en protestas emblemáticas durante el primer año de pandemia, algunas de las cuales tienen como principales protagonistas a sectores que manifestaron su repudio al gobierno nacional. Entre estas se puede hacer mención de algunas emblemáticas, como el llamado \#17A (en alusión al 17 de agosto de 2020, aniversario de la muerte del general San Martín), que es la primera movilización opositora masiva que se realiza en diferentes ciudades en simultáneo (Buenos Aires, Mendoza, Córdoba, Rosario, Santa Fe, Mar del Plata, entre otras). La protesta es convocada por figuras del principal partido opositor al gobierno 
(PRO) y en cuanto a los repertorios utilizados, se combinan caravanas de autos y banderazos ${ }^{8}$.

Por su parte, los llamados bicicletazos son utilizados más claramente por sectores juveniles movilizados y para otro tipo de demandas. Un caso paradigmático son las y los jóvenes trabajadores de plataformas de aplicaciones como Rappi, Glovo y Uber en reclamo por las condiciones precarias de trabajo. El formato es significativo porque la principal herramienta de trabajo (las bicicletas) se convierte, además, en el vehículo con el que realizan las acciones de protesta en diferentes centros urbanos, como Buenos Aires y Córdoba.

Se pueden mencionar, también, los bicicletazos organizados por el colectivo Les Jóvenes y agrupaciones socioambientales, como Jóvenes por el Clima, en contra de un proyecto presentado en la Legislatura porteña que habilitaba la privatización de un predio público, con acceso al Río de la Plata, para la construcción de edificios. Estas agendas son previas a la pandemia, pero encuentran condiciones de actualización en un nuevo escenario pandémico en el que se revaloriza el uso social de los espacios públicos.

En sintonía con los trabajos que exploran las relaciones entre presencialidad y virtualidad en las acciones colectivas juveniles, el relevamiento nos permite pensar que el uso de formatos de acción digital preexiste a la pandemia. La disminución de los formatos presenciales y el crecimiento en el uso de los virtuales no quiere decir que las organizaciones juveniles abandonen masivamente las calles; tampoco el uso de repertorios de acción presenciales debe interpretarse, per se, como un desafío hacia las medidas de aislamiento.

\footnotetext{
${ }^{8}$ Acción que quedó asociada a la movilización de sectores de derecha que se reivindican como a-políticos. El uso de banderas argentinas expresa su distanciamiento con el uso de banderas políticas y la presentación pública de los manifestantes tiene que ver con reconocerse como «ciudadanos». Estas acciones tienen un sesgo generacional marcado de adultos y adultos-mayores, con alguna participación de grupos como Jóvenes Libertarios o Jóvenes Republicanos.
} 
La mitad de las organizaciones (14/28) manifiesta su acuerdo con las medidas tomadas por el gobierno durante la pandemia (como ATE, el CE, Descendientes de Victoria, Frente Joven, Jóvenes por el Clima, FPDS, Juventud Sindical, La Cámpora, La Poderosa, el MTE, el MNCI, UES, UTT, Zona La Plata), mientras que cerca de un tercio (9/28) se manifiesta en contra. Algunas sostienen que están en desacuerdo (como la Juventud Socialista y Million Dollar Vegan), mientras que otras afirman estar muy en desacuerdo (como el Centro de Estudiantes del CNBA, Frente Joven, Juventud del Pro, Marcha por la Vida, Pibes Liberatorios, Jóvenes del Partido Demócrata y Federación Agraria Argentina). Así, las lecturas que hacen sobre las medidas de gobierno no se desprenden de forma mecánica de sus valoraciones sobre las medidas de aislamiento. En efecto, más de la mitad (15) sostiene que las medidas de aislamiento son entre muy razonables y razonables. Tres organizaciones (FAA, Marcha Por la Vida y Pibes Libertarios) afirman que no son nada razonables y que son impulsadas para controlar a la población y dos organizaciones (JPD y Repartidores Unidos) que no son razonables porque no se hizo lo suficiente para cuidar a la población. Finalmente, cinco organizaciones dan otro tipo de respuestas, que tienen que ver con que consideran razonables las medidas pero insuficientes para enfrentar las desigualdades, entre estas se encuentran el Centro de Estudiantes del Colegio Nacional de Buenos Aires, Franja Morada, la Juventud Socialista, Million Dollar Vegan y La Campaña por el derecho al aborto legal, seguro y gratuito. La opción por el uso de las calles, a la que - como mencionamos - apelan diferentes organizaciones durante las medidas de ASPO y DISPO, involucra de forma mayoritaria el uso de protocolos para evitar contagios.

Para finalizar, presentamos dos acciones colectivas relevantes para reflexionar sobre los solapamientos entre la dimensión presencial y virtual. La primera tuvo lugar el 17 de octubre, en la conmemoración del «Día de la lealtad peronista». Frente a la vigencia de las medidas de ASPO, el Frente de Todos 
definió organizar una marcha virtual en la plataforma 75octubres.ar. Se convocó a la participación en esta acción por medio de la elección de un avatar con el que las personas podrían participar situándose en alguno de los escenarios virtuales: el Obelisco, la Plaza de Mayo, el Congreso de la Nación, la avenida de Mayo o la avenida 9 de Julio. Además se realizaría un acto virtual, en el que tendrían parte tradicionales oradores de esta jornada, como la Confederación General del Trabajo y el presidente de la nación. Además de la convocatoria oficial, diferentes organizaciones lanzaron sellos propios para participar de la movilización virtual, se sumaron tuits de referentes y funcionarios ${ }^{9}$, hashtags (como \#75octubres), mappings y proyecciones sobre edificios ${ }^{10}$, así como también algunos sectores sindicales convocaron movilizaciones presenciales en la Plaza de Mayo. El colapso de la página frente a lo que se difundió públicamente como un hackeo llevó a que en las organizaciones comenzaran a circular mensajes en los que se invitaba a realizar una caravana de autos junto con consignas específicas que se difundieron en redes, como \#El17nadiesebaja, \#caravanadelalealtad, entre otras.

Otro ejemplo son las movilizaciones que tuvieron lugar durante los debates parlamentarios en torno a la legalización del aborto, principalmente de grupos de feministas, así como también de colectivos que adoptaron un pañuelo celeste para manifestar su repudio de la legalización del aborto o en «defensa de las dos vidas». Aquellas jornadas mostraron la contundencia de la movilización en las calles y de las vigías, en las que se acompañó el debate parlamentario en la Plaza de los Dos Congresos. La participación de referentes históricas del

\footnotetext{
${ }^{9}$ A modo ilustrativo, uno de los integrantes de la mesa nacional de conducción de La Cámpora y ministro del Interior, Wado de Pedro, tuiteó: «Este 17 copamos las redes. Más leales que nunca a las banderas de Perón, Evita, Cristina y Alberto».

${ }^{10}$ El mapping consiste en la proyección de consignas o imágenes sobre edificios o lugares públicos. Durante la pandemia se convirtió en un recurso valorado en América Latina para poder dar visibilidad pública a demandas en reemplazo de acciones presenciales. Durante esta jornada, jóvenes del Movimiento Evita de Capital Federal proyectaron videos y consignas alusivas como «leales a nuestro pueblo».
} 
feminismo y la masiva asistencia de la «generación glitter» (Elizalde, 2019) constituyeron un aspecto fundamental para que, luego de siete presentaciones, la ley tuviera media sanción en la Cámara de Diputados. Ese aprendizaje, así como la relevancia que adoptó la dimensión performática de este reclamo ${ }^{11}$, explica la importancia que tuvo la movilización en las calles durante los nuevos debates del año 2020, aspecto que se pone de manifiesto en unos de los hashtags utilizados para convocar a la movilización: \#SaleSiSalís — además de las campañas con tuits con las consignas \#SeráLey, \#AbortoLegal2020, \#EsAhoraSenado que alude a la importancia de asistir presencialmente a la movilización. Las concentraciones tuvieron lugar durante las jornadas en las que se debatió el proyecto de ley en la Cámara de Diputados (11 de diciembre, en la que tuvo media sanción con 131 votos a favor, 117 en contra y 6 abstenciones) y en el Senado (el 30 de diciembre de 2020), donde resultó aprobada con 38 votos positivos, 29 negativos y 1 abstención). En ambos casos, los grupos movilizados pusieron énfasis en la importancia de mantener distancia social y cuidados.

Los análisis acerca de las relaciones entre las prácticas online-offline que se han incorporado para pensar el activismo juvenil (Reguillo, 2017; Feixa, 2014) muestran que las disputas por la visibilidad y el poder se definen en función de las cambiantes articulaciones entre esos dos escenarios (Galindo y Alves, 2015). En tal sentido, como se manifiesta en los ejemplos, la visibilidad de los grupos o la urgencia de ciertos reclamos no siempre pueden sostenerse con la mera virtualidad, incluso en tiempos de pandemia. En estos casos se evidencia el valor de «política de los cuerpos» (Vázquez y Vommaro, 2011), esto es, el carácter indelegable del «estar allí»».

${ }^{11}$ La apropiación de las calles con mujeres haciendo uso de pañuelos verdes, el desarrollo de performances y la adopción de elementos performáticos en las acciones públicas muestran, como sostiene Melucci (1988) en el análisis de los llamados nuevos movimientos sociales, que este tipo de grupos son relevantes no solo por lo que dicen o reclaman, sino por cómo lo hacen. 
Sin embargo, los ejemplos también ilustran la complementariedad entre las acciones presenciales y virtuales y desincentivan las interpretaciones que postulan que el uso de unas herramientas va en detrimento de las otras. Al vínculo recíproco entre lo presencial (offline) y lo virtual (online) proponemos incorporar, además, otro elemento: la centralidad del on live. Esto es, el peso que poseen las transmisiones en vivo o por streaming de las acciones. Allí podemos ver cómo se modulan las relaciones entre lo presencial y lo virtual y se pone en juego la posibilidad de redefinir el curso de las acciones, la convocatoria a la participación de más activistas o, incluso, la denuncia de las represiones mientras las acciones colectivas tienen lugar.

Las organizaciones que formaron parte del relevamiento han realizado, en todos los casos, acciones virtuales durante la pandemia y una gran proporción ha realizado acciones colectivas que involucran la presencialidad. Por ello, antes de afirmar que estas disminuyen $-\mathrm{o}$ aumentan - se vuelve imperioso preguntarse por la fisionomía de dichas transformaciones, explorando cómo esos cambios se ponen en juego entre lo presencial y lo virtual. Para ello, vale considerar cómo se movilizan saberes digitales en acciones militantes que, como vimos, preexisten a la pandemia pero que en el nuevo contexto se actualizan. De acuerdo con esto, también es preciso reconsiderar las estrategias metodológicas para el estudio cuantitativo de las acciones colectivas que, en lugar de considerar solamente la dimensión presencial de las acciones contenciosas, permita abordar estas yuxtaposiciones.

Vale señalar que las acciones colectivas estudiadas durante la pandemia no solo permiten ver la exacerbación de las herramientas virtuales y digitales, sino también la actualización de formatos clásicos, como por ejemplo los desarrollados por organizaciones que refuerzan entre grupos de estudiantes aquellas formas de militancia territorial vinculadas con acciones como distribución de alimentos. También se exacerba la pata territorial de la militancia partidaria, al igual que en otros contextos de crisis, como podemos ver en la 
participación de La Cámpora en la inscripción de personas en las campañas de vacunación. Además, organizaciones con fuerte inserción en barrios populares han profundizado su participación activa en comedores y merenderos populares por medio de la distribución de alimentos y de elementos de higiene. Algunas de estas dieron visibilidad pública a las dificultades que enfrentaban los sectores populares para llevar adelante las medidas de aislamiento. En tal sentido, se destaca el papel de grupos como La Garganta Poderosa, organización que puso en agenda los problemas de acceso a condiciones dignas de vivienda en algunos barrios populares, asentamientos o villas miseria. En especial en la villa 31, ubicada dentro de la Ciudad de Buenos Aires, en la que no hubo agua potable durante los primeros días del ASPO y sus habitantes debían comprar bidones de agua para mantener mínimas condiciones de higiene en medio de la pandemia ${ }^{12}$.

El desarrollo de acciones territoriales y de solidaridad o ayuda mutua presenciales pueden pensarse como estrategias de contención durante la crisis sanitaria pero, además, como ámbitos para la construcción y consolidación de redes y estrategias colectivas que persistan en el tiempo y permitan incidir en el escenario pospandemia. Siguiendo a Della Porta (2020) en su análisis sobre el caso europeo, esto muestra la relevancia que poseen los colectivos para intervenir públicamente en la tematización de las inequidades como plataforma para la construcción de (nuevas) agendas militantes a futuro.

\subsection{LOS COLECTIVOS EN PANDEMIA. IMPACTOS Y MODOS DE ORGANIZACIÓN}

En la sección anterior analizamos la manera en que la relación entre presencialidad y virtualidad se pone en juego durante la pandemia. Como vimos, el activismo juvenil puede pensarse en la articulación entre las acciones online,

\footnotetext{
${ }^{12}$ Este caso tuvo una repercusión pública destacada por la muerte (por coronavirus) de Ramona Medina, una de las voceras de este reclamo desde la organización.
} 
offline y en vivo. Esto dista de ser una novedad, sin embargo, la pandemia genera condiciones para transformar parcialmente este tipo de articulaciones. Ahora bien, ¿cómo impactan las medidas de aislamiento al interior de los grupos?, ¿en qué sentido es posible virtualizar los vínculos militantes?, ¿cómo impactan sobre las estrategias organizativas el impulso de medidas gubernamentales que limitan una de las cuestiones más valoradas para el desarrollo de los compromisos militantes: el estar juntos?

En este apartado analizamos cómo se ponen en juego las relaciones entre presencialidad y virtualidad en la vida cotidiana de los grupos. Según los resultados del relevamiento de organizaciones juveniles, 22 de los 28 colectivos señalan que la pandemia ha tenido impacto en la vida interna de los grupos. El principal aspecto que señalan tiene que ver con adaptar su funcionamiento a las restricciones. En 11 de los 28 grupos se menciona que las dificultades organizativas que involucra la no presencialidad han propiciado una mayor apertura de los debates internos. Por el contrario, casi un tercio (8/28) afirma que en este escenario se han centralizado mucho más las decisiones en los líderes de los grupos. Una de cada cuatro organizaciones afirma que las decisiones se han vuelto más lentas.

Al momento de explorar los problemas principales que enfrentan los grupos, 24 de las 28 organizaciones mencionan las dificultades que reviste organizarse de modo virtual. En más de la mitad de los grupos mencionan que muchas personas han dejado de participar y también que se vuelve más difícil convocar a nuevos activistas (12/28). Finalmente, en una de cada cuatro organizaciones el problema que presenta la pandemia es que las personas disponen de menos tiempo para reunirse. En otras palabras, las dificultades que involucra el aislamiento tienen que ver con la gestión de estrategias organizativas entre quienes son miembros, con los incentivos para permanecer dentro de los grupos y con las limitaciones que encuentran para sumar más o nuevos miembros. 
Ahora bien, al igual que notábamos con las acciones colectivas, la investigación permite advertir que las formas de comunicación interna de los grupos se encontraban fuertemente virtualizadas de modo previo a la pandemia. De acuerdo con las encuestas, las y los integrantes de los colectivos hacían uso de Whatsapp, Facebook, Instagram, Twitter, Tik Tok o correo electrónico como formas de comunicación interna habituales. La única incorporación novedosa son plataformas como Zoom, Jitsi o Google Meet para poder establecer comunicaciones, organizar charlas o encuentros colectivos.

En varios casos, las y los activistas valoran la conversión a formato digital de algunos de estos eventos en la medida en que representa una ampliación de las formas de participar, sobre todo en organizaciones con grandes estructuras nacionales, en las cuales poder trasladarse a grandes reuniones resulta difícil y costoso. Un caso ilustrativo es la realización de forma virtual de un histórico evento de formación política de las y los jóvenes militantes del Partido Socialista, que se realiza de forma ininterrumpida desde 1989. Se trata de un campamento que tiene lugar de modo presencial a lo largo de varios días, en los cuales se realizan talleres, espacios de discusión con dirigentes del partido, asambleas y actividades recreativas que constituyen un espacio de socialización política de las militancias juveniles de este partido (Cozachcow, 2020). El campamento número 32, previsto para enero de 2021, se realizó de forma virtual, con una extensión de cinco días en los que tuvieron lugar espacios de debate y talleres de formación política. En los mismos se abordaron las agendas partidarias y juveniles y se tematizaron diferentes aspectos vinculados con el contexto de la pandemia. A continuación, en la Figura 1 se puede ver la gráfica de una de las convocatorias lanzadas por la Juventud Socialista (JS) y el Movimiento Nacional Reformista (MNR), brazo universitario del Partido Socialista. 
FIGURA 1. GRÁFICA DE DIFUSIÓN DEL CAMPAMENTO NACIONAL DE LAS JUVENTUDES SOCIALISTAS DE ARGENTINA, 2021

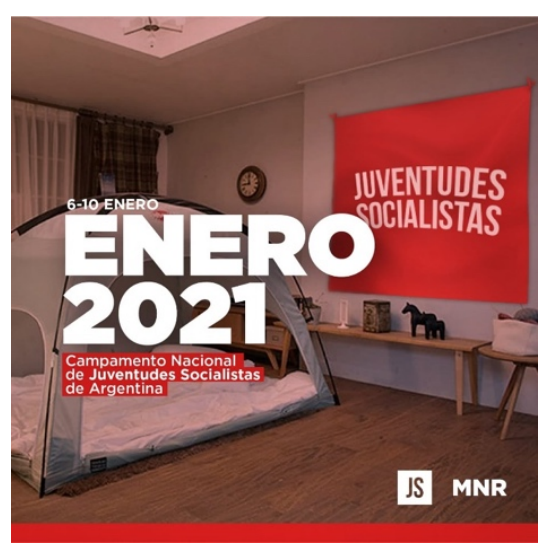

Fuente: Tomado del perfil oficial de Facebook de Juventudes Socialistas de Argentina, 2021.

(https://www.facebook.com/JuventudSocialistaArg/photos/a.1685275371586486/3534 199070027431/).

Ahora bien, no todas las acciones parecen susceptibles de ser virtualizables. A modo de ejemplo, en algunas asambleas en línea se debate sobre la legitimidad de la instancia virtual en la toma de decisiones relevantes, como por ejemplo la renovación de autoridades. Podemos citar, a modo ilustrativo, el caso de la Federación Universitaria de Buenos Aires (FUBA) y la Federación Universitaria Argentina (FUA). En agosto de 2020 se realizó una reunión de la Junta Representativa de la FUBA en la que participaron los representantes de centros de estudiantes de las trece facultades de la Universidad de Buenos Aires, donde se resolvió suspender las elecciones estudiantiles debido a las restricciones en el escenario de la pandemia, para poder realizarlas de modo presencial. Algunas agrupaciones de izquierda impugnaron esta decisión y sostuvieron que se trataba de argucias para prorrogar los mandatos de las agrupaciones. La Juventud del Partido Socialista de los Trabajadores (PTS) propuso la realización de otros encuentros virtuales entre estudiantes y agrupaciones con el fin de construir una plataforma de temas vinculados con la coyuntura pandémica, que iba desde impugnar la suspensión de las elecciones hasta la tematización de las clases virtuales y la precarización docente. El punto a destacar es el debate que 
suscita y la falta de legitimidad que le confieren a los mecanismos virtuales para tomar decisiones relevantes para los grupos, por ejemplo, para llevar adelante elecciones en las que se designan autoridades. Es interesante, no obstante, que la impugnación que se realiza desde este espacio partidario — con fuerte inserción en la vida universitaria de la UBA - apele a un formato igualmente virtual para elaborar una respuesta a lo que perciben como un problema de representación política.

En otros casos, los espacios de juventud al interior de partidos y sindicatos, así como también algunas agrupaciones estudiantiles, toman la coyuntura de la pandemia como marco para el desarrollo de actividades de formación interna con sus miembros. Estos eventos son difundidos por distintas redes sociales digitales y, en algunos casos, también son abiertos al público. A título ilustrativo, podemos mencionar los realizados por el Consejo Federal de la Juventud Peronista, rama juvenil del Partido Justicialista. A continuación, en la Figura 2 se incluye un flyer utilizado en estas actividades.

FIGURA 2. GRÁFICA DE DIFUSIÓN DE EVENTO VIRTUAL DE FORMACIÓN POLÍTICA DEL CONSEJO FEDERAL DE LA JUVENTUd PERONISTA

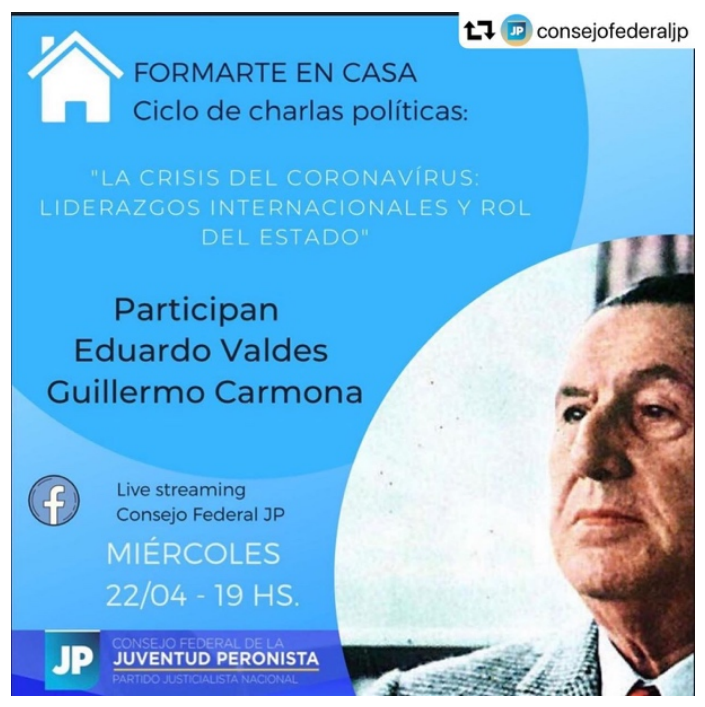

Fuente: Tomado del perfil oficial de Facebook de Juventud Peronista, 2021, https://www.facebook.com/JuventudSocialistaArg/photos/a.1685275371586486/35341 99070027431/) 
Las ideas presentadas permiten pensar en las cambiantes relaciones entre lo presencial y lo virtual, tanto en lo referido a las acciones contenciosas visibles como también en la construcción de estrategias de organización interna. Los formatos digitales no son considerados novedosos por las y los jóvenes activistas, ni tampoco para sus organizaciones. Sin embargo, la pandemia propone desafíos en relación con sus quehaceres habituales vinculados con la presencialidad. Aun cuando algunas de esas acciones pueden hacerse virtuales, otras no admiten este formato. En algunos casos la virtualidad aparece como una suerte de compensación en tiempos excepcionales, como se puede ver en el campamento virtual de la Juventud Socialista, cuyo formato presencial difícilmente pueda reemplazarse. Asimismo, la virtualidad parece un formato interesante para algunas acciones, pero ilegítimo para otras (como para renovar autoridades). La eficacia de los mecanismos virtuales varía en función de las agendas. Así, participar de un «tuitazo» permite construir un tema como tendencia y ayuda a colocarlo sobre la agenda pública, como podría ser el apoyo o la oposición a la legalización del aborto. Sin embargo, esto se vuelve complementario con acciones que requieren «poner el cuerpo» de forma presencial, especialmente en un tema en el que los cuerpos forman parte del campo de batalla. Finalmente, la participación en redes o por medios virtuales pareciera variar en función de los perfiles de las y los activistas. La participación cotidiana por medio de acciones en red aparece, desde la perspectiva de las organizaciones, como un «problema», puesto que dificultan tanto el reclutamiento como la permanencia dentro de los grupos.

\section{Agendas y CaUSAS MiLitantes durante la PANDEMIA}

De acuerdo con los resultados de nuestra investigación, las agendas militantes se vieron modificadas de diferentes maneras durante la pandemia. En algunos casos, desde los colectivos se afirma que las agendas no parecen sufrir 
grandes transformaciones con la pandemia y se mantienen los temas de siempre. En este grupo encontramos juventudes partidarias (como La Cámpora y la Juventud del Partido Demócrata, la primera oficialista y la segunda opositora); a la Juventud Sindical; una organización socioterritorial (el Frente Popular Darío Santillán) y un colectivo que desarrolla acciones contra la legalización del aborto (Marcha por la Vida).

Otros grupos (10/28) afirman que no sufrieron cambios en sus agendas, pero sí actualizaciones. En esta situación se encuentran organizaciones ambientalistas, como Jóvenes por el Clima y Rebelión o extinción; estudiantiles (como el Centro de Estudiantes del CNBA y la UES), sindicales (como Repartidores Unidos), rurales (como la UTT), partidarias (como la JS), de feminismos y disidencias (como la Campaña Nacional por el derecho al aborto y Zona La Plata) y antiderechos (como Frente Joven). El único tipo de organizaciones que no encontramos representada en esta respuesta son las de tipo socioterritorial. Más de la mitad de los grupos señala que los temas de los que se ocupan sus organizaciones cambiaron desde el inicio de la pandemia (13/28). En un solo caso se afirma que dicho cambio fue drástico; en el resto de los grupos sostienen que hay modificaciones ligadas con la integración de asuntos nuevos en sus agendas. Entre estos se observan agendas de la pandemia, como las vinculadas con el acceso a la salud, a la educación, a las tecnologías y a la conectividad, así como la problematización de diferentes manifestaciones de las desigualdades.

Las maneras en que los grupos modifican, actualizan o transversalizan sus agendas durante la pandemia son diferentes. En el caso de las juventudes de la Federación Agraria Argentina, colectivo que nuclea a pequeños y medianos productores, se menciona la incorporación de cuestiones relativas a conectividad dentro de sus agendas. En la juventud del sindicato ATE se alude a la ampliación de temas en torno al trabajo en pandemia, fundamentalmente cuestiones relativas a la reglamentación del teletrabajo. 
En el caso de Million Dolar Vegan, notamos que un tema previamente tematizado encuentra en el nuevo contexto condiciones de actualización. Nos referimos, a modo ilustrativo, al modo en que comienzan a reflexionar acerca de las relaciones entre la industria ganadera y el surgimiento de las pandemias.

Otra situación interesante tiene que ver con los casos en que encontramos el desplazamiento de agendas entre grupos durante la pandemia. Podemos pensar, por ejemplo, la presencia de temáticas ligadas con cuestiones ambientales en grupos que no son ambientalistas ni suelen tener estos temas como prioritarios, como notamos en la juventud de la Asociación de Trabajadores del Estado, que además del teletrabajo, recién mencionado, y el impuesto a las grandes fortunas ${ }^{13}$, aluden al ambientalismo como cuestión emergente.

En otros casos, como en las agendas de las llamadas «nuevas derechas», se menciona la cuestión de los «derechos humanos» como asunto novedoso. Esto resulta interesante para el caso argentino, donde la referencia al término activa una tradición de militancia vinculada con organismos de víctimas $-\mathrm{o}$ familiares de víctimas - de la última dictadura militar que sostienen reclamos de «memoria, verdad y justicia». Los usos de esta expresión en el seno de estos grupos muestra una agenda «nueva» en su quehacer militante que, además, disputa los sentidos cristalizados en torno a la noción de «derechos humanos» en la cultura política local. En concreto, porque apelan a la misma para impugnar al gobierno nacional y a las medidas de aislamiento social desde la reivindicación de una idea negativa e individualista de libertad.

Finalmente, hay agendas transversales a los grupos que tienen más que ver con el común reconocimiento de los asuntos emergentes durante la pandemia

${ }^{13}$ La Ley 27605/2020, sancionada por el Congreso de la Nación establece el cobro de un Aporte Solidario y Extraordinario a las grandes fortunas para ayudar a morigerar los efectos de la pandemia. Fue objeto de controversias y manifestaciones públicas de oposición por parte de reconocidos empresarios. A la vez, se integró en las agendas de diferentes colectivos y movimientos sociales que se mostraron a favor. 
que con los campos de experticia política y militante de los grupos. En tal sentido, el acceso a las tecnologías e internet aparece entre colectivos diferentes como la agrupación estudiantil radical Franja Morada, grupos partidarios como Descendientes de Victoria, agrupaciones agrarias como la Federación Agraria o los movimientos socioterritoriales La Poderosa y el MTE. De igual manera, las agendas que tocan cuestiones educativas se mencionan por grupos tan disímiles como el Movimiento Nacional Campesino Indígena, Centros de Estudiantes Secundarios o la Juventud del PRO. Aunque cada colectivo enmarca y produce interpretativamente de maneras diversas estas agendas, con una impronta específica, no deja de ser relevante atender a la construcción de plataformas comunes entre grupos juveniles.

Otro elemento que surge del trabajo de campo tiene que ver con la manera en que diferentes colectivos incorporan a sus temáticas principales otras que son transversales. A título ilustrativo, en los paros internacionales y bicicletazos que realizan agrupaciones que nuclean trabajadores de aplicaciones se puede observar el uso del lenguaje inclusivo en las consignas públicas que sostienen (en las que hablan de sí mismos como «trabajadorxs precarizadxs»), en los apelativos que les dan a sus organizaciones («Rappi y Furioses» ${ }^{14} \mathrm{o}$ «Pibes y Pibas contra la precarización»), así como también en los usos del pañuelo verde —que simboliza el apoyo a la legalización del aborto- que se integra a las estéticas contestatarias. Así, aunque las acciones de protesta tienen otras demandas y sus agendas militantes giran en torno a otros tópicos (como la precarización laboral), en estos gestos se puede ver la apropiación y transversalidad de demandas que sí constituyen el centro del quehacer militante en otras organizaciones. Esto mismo se reconoce en la adhesión a las agendas contra la violencia institucional, en particular frente a hechos puntuales vinculados con jóvenes, como se pudo ver en la adhesión al pedido de búsqueda y aparición de Facundo Astudillo Castro,

${ }^{14}$ El nombre refiere al filme Rápido y furioso, apela al uso de un lenguaje inclusivo y juega con el nombre de la empresa «Rappi». 
joven que estuvo desaparecido durante un mes y medio luego de ser detenido por la Policía de la Provincia Buenos Aires tras haber violado las medidas de restricción de circulación ${ }^{15}$.

Las ideas presentadas permiten pensar, por un lado, en la emergencia y/o revitalización de asuntos que no estaban en las agendas militantes juveniles, fundamentalmente en cuestiones ligadas con la crisis sanitaria de la pandemia y las restricciones a la movilidad. Por otro lado, en una adaptación o resignificación en el marco del nuevo contexto de temáticas ya presentes en las agendas de las organizaciones. Entre estas, se destacan temas como acceso a la educación, conectividad, desigualdades y violencia institucional.

\section{Las disPutas POR DeRECHA. MOVIlizaciones Y GRUPOS JUVENILES EN EL ESPECTRO ANTIPROGRESISTA}

El último punto a trabajar tiene que ver con uno de los principales emergentes de la movilización juvenil durante la pandemia: las juventudes de derechas. Aunque varios colectivos existen de forma previa, cobran visibilidad durante las movilizaciones callejeras, así como en las redes sociales, en el período de pandemia. Esto no puede pensarse como una mera circunstancia, sino más bien como resultado de un contexto de oportunidad política para la visibilización de estos grupos y sus agendas, como intentamos mostrar.

Uno de los casos emblemáticos es Jóvenes Republicanos, espacio juvenil que forma parte de Unión Republicana, una de las líneas internas del partido Propuesta Republicana (PRO). Esta organización ha tenido fuerte repercusión mediática a partir de la participación en acciones performativas desarrolladas en el marco de movilizaciones opositoras más amplias. La más destacada fue aquella

${ }^{15}$ Durante el tiempo que estuvo desaparecido, diferentes colectivos recuperaron y movilizaron la consigna «¿Dónde está Facundo?». 
que tematizó el escándalo por los «vacunados V.I.P.», episodio por el cual políticos y personajes públicos sortearon el orden de asignación de turnos para las vacunas. Esto le valió la renuncia al ministro de Salud en el mes de febrero de 2021. El 27 de febrero se organizó una movilización opositora convocada en redes con el hashtag \#27F y \#Argentinazo. Allí, los integrantes de Jóvenes Republicanos realizaron una performance que consistió en la colocación de bolsas mortuorias. Por medio de estas buscaban representar los cuerpos sin vida de aquellas personas que «no pudieron vacunarse», como indicaban las consignas utilizadas ese día. A su vez, las bolsas llevaban los nombres de las personas que sí habían accedido a las vacunas. Entre los nombres, figuraban referentes de organismos de derechos humanos - como Estela de Carlotto, presidenta de la Asociación Abuelas de Plaza de Mayo — vinculados con reclamos por memoria, verdad y justicia frente a los crímenes de la última dictadura militante que no habían accedido de forma espuria a la vacunación. La mención de estas figuras y la realización de una performance que emulaba a las protestas realizadas por organismos de derechos humanos frente a la desaparición forzada de personas, fue interpretada como un mensaje amenazante. Por ello, la acción generó un amplio espectro de repudios que incluyó a Alberto Fernández, presidente de la nación. Sin embargo, la agrupación defendió el reclamo y el formato elegido.

Otros grupos que cobraron notoriedad son las juventudes libertarias, como Pibes Libertarios, espacio que se define en su perfil de Instagram como una «organización política argentina que se moviliza en defensa de la vida, la libertad y la propiedad privada». Algunos de los colectivos — como Frente Joven, Marcha por la Vida, Pibes Libertarios y sectores de la JPRO (liderados por la diputada nacional Dina Rezinovsky) — sostienen una agenda en contra de la legalización del aborto y también tuvieron una participación visible en las movilizaciones durante los debates parlamentarios.

La visibilidad que han ganado estos colectivos puede pensarse como resultado de estas acciones con impacto público, así como también del repliegue 
de la movilización en las calles por parte de las organizaciones más afines al gobierno nacional a partir de su adhesión a las medidas de aislamiento. En tal sentido, las restricciones definidas por el gobierno constituyeron un marco de oportunidad para los grupos que se movilizan no solo en contra de las restricciones, sino además del gobierno (Vicente y Saferstein, 2020; Soto Pimentel et al., 2021).

En línea con trabajos anteriores (Vázquez y Cozachcow, 2020), es posible afirmar que la disputa de las derechas se reconoce en dos planos. Por un lado, en la disputa sobre la movilización en calles. Uno de los jóvenes que contactamos al momento de gestionar la aplicación del cuestionario de Pibes Libertarios colocó un comentario adicional en la encuesta, en el que mencionó: «Muchas de las preguntas estaban dirigidas a cómo la pandemia "perjudicó" nuestra tarea como agrupación. En nuestro caso, esas dificultades no aplican. Sumamos cientos de jóvenes a nuestras filas, crecimos y nos movilizamos como nunca». Es decir, desde su punto de vista, la pandemia representa un momento políticamente productivo, un contexto para tener visibilidad, instalar nuevos temas en la agenda pública y reclutar nuevos militantes.

Por otro lado, estos sectores que se autodefinen de «derecha» disputan los sentidos y modos de representar políticamente a las juventudes, cuestión que se ha exacerbado durante la pandemia. En tal sentido leemos la construcción de una «épica de la resistencia» (Vicente y Saferstein, 2020) que moviliza adhesiones políticas y militantes juveniles y que se vale de recursos estético-políticos y culturales como las acciones performativas mencionadas.

Este es un fenómeno que diferentes investigadores registran en los últimos años (Goldentul y Saferstein, 2019) y que puede pensarse en relación con un ciclo político más amplio, en el cual las derechas en diferentes países de América Latina buscan posicionarse como la alternativa a los progresismos, leídos como parte del statu quo. Según Stefanoni (2021), la imagen de la rebeldía, 
la desobediencia y la transgresión, históricamente asociada a sectores de izquierda, fue adoptada por sectores de derecha que «disputan a la izquierda la capacidad de indignarse frente a la realidad y de proponer vías para transformarla» (p. 15). En tal sentido puede leerse la idea de «incorrección política» que buscan enaltecer varias de las organizaciones mencionadas.

Otro de los aspectos que nos propusimos analizar en el relevamiento son las visiones que tienen sobre las relaciones entre democracia y pandemia. Reconocemos una mirada negativa sobre la democracia en tiempos de pandemia, aunque en el caso de la Juventud del PRO esta visión es más moderada. De cinco organizaciones de derecha encuestadas, tres (Marcha por la Vida, JPD, Pibes Libertarios) consideran que «esto no es una democracia de verdad»; en Frente Joven consideran que «vivimos en una democracia, aunque tiene muchas deficiencias» y desde Jóvenes PRO afirman que «vivimos en una democracia con los problemas habituales de otros países». Los grupos autodefinidos como «derecha» sostienen que su valoración de la democracia ha cambiado durante la pandemia. Los motivos que dan giran en torno a lo que perciben como atropellos contra las libertades individuales. Las medidas de aislamiento «han hecho que nos comprometamos aún más en la defensa de la república, la democracia y los derechos humanos» (Jóvenes PRO); «por las restricciones de los derechos individuales, gobernar por Decretos de Necesidad y Urgencia, ir en contra de la Constitución nacional» (JPD); «porque han robado las libertades individuales y hay un gobierno totalitario que busca ejercer el poder mediante el miedo» (Marcha por la Vida); «porque quedó probado con más evidencia que nunca que vivimos bajo una tiranía de las mayorías y que esta tiranía no respeta nuestros derechos constitucionales» (Pibes Libertarios).

Aunque todos los grupos se reconocen como opositores, las evaluaciones que hacen de las medidas de aislamiento definidas por el gobierno nacional presentan algunos matices. En dos organizaciones sostienen que las medidas son «algo razonables. El aislamiento tiene sentido, pero es importante cuidar la 
economía para el día después» (Frente Joven y Jóvenes PRO). En Marcha por la Vida y Pibes Libertarios señalan que son «nada razonables. Las medidas de aislamiento son creadas por gobiernos que quieren controlar a la población» y desde JPD sostienen que no son «nada razonables, no se hizo lo suficiente para cuidar a la población».

Finalmente, quisimos indagar cuál era el parecer de los grupos en relación con los movimientos negacionistas y anticuarentena que plantean que el coronavirus no existe o no tiene la importancia que se le otorga. Entre los colectivos que se autoperciben de «derecha» hay una mirada positiva sobre aquellos movimientos. En tres casos sostienen que son movimientos «que defienden las libertades que nos quieren quitar a las personas los gobiernos y los poderes económicos» (Marcha por la Vida, Pibes Libertarios, JPD); en una de las organizaciones adhieren a la idea de que «son movimientos que se preocupan por la situación económica de la mayoría de la gente que se ve muy perjudicada» (Frente Joven) y en Jóvenes PRO, la organización más grande de las cinco, afirman que no hay una única opinión sobre el tema dentro del grupo.

\section{CONSIDERACIONES FINALES}

En este artículo realizamos una aproximación al estudio de las acciones colectivas juveniles en la pandemia. El trabajo propone explorar los efectos que posee la pandemia, más concretamente las medidas destinadas a contener los contagios, sobre las maneras de protestar, organizarse e intervenir en el espacio público. Lejos de poder afirmar que las restricciones a la circulación producen un achicamiento del espacio público, este y otros trabajos muestran que las acciones colectivas siguen teniendo lugar. En algunos casos de forma presencial $y$, en otros, virtual; al mismo tiempo que en buena parte de los casos el desarrollo de las estrategias de movilización y organización colectiva combina modalidades presenciales, en línea y en vivo. Sin embargo, es indudable que la pandemia 
posee efectos. En algunos casos, estos se manifiestan en las maneras de hacer uso de las calles (por ejemplo, con caravanas) y en otros impacta sobre las rutinas y hábitos organizativos de los grupos. Sostener el activismo en línea representa, para los grupos, un problema con el que deben lidiar.

El análisis de los temas y las agendas militantes permite distinguir entre agendas de la pandemia y en la pandemia. Entre las primeras, nos encontramos con temáticas que emergen producto del nuevo contexto, como por ejemplo, la virtualización de la educación (que incluye reclamos por conectividad como por la vuelta a la presencialidad); las condiciones de trabajo en torno a las actividades «esenciales» (tanto personal de salud como repartidores de aplicaciones); la violencia institucional por parte de fuerzas de seguridad hacia jóvenes o las medidas de aislamiento en sí (por lo general forma parte de las agendas de los espacios de las derechas que reclaman contra la restricción a las libertades individuales). Entre las agendas en la pandemia, nos encontramos con temáticas ambientales (particularmente la ley de humedales), urbanas (como las movilizaciones por la venta de terrenos públicos en la Ciudad de Buenos Aires) y la despenalización del aborto.

El artículo nos invita a pensar las inflexiones que tienen lugar en el desarrollo de repertorios de acción colectiva, así como en las agendas de los grupos. Sin embargo, ambas cuestiones pueden estudiarse de modo separado. En otros términos, encontramos en los grupos agendas y temas que organizan su quehacer militante que preexisten a la pandemia $\mathrm{y}$, en principio, no están afectados por la misma. Sin embargo, en ocasiones, los modos de poner en escena estas agendas sí aparecen modificados en un escenario de presencialidad restringida o limitada, como se puede ver en el uso de las caravanas. En otros casos, los temas o la manera de abordarlos se ven permeados por cuestiones relativas a la crisis sanitaria, aún cuando utilicen formatos de protesta de la misma manera que lo hacían en la prepandemia. 
El trabajo permite afirmar que las medidas de aislamiento no pueden pensarse solamente como un contexto de restricción a las movilizaciones. Primero porque, como vimos, hay acciones colectivas (presenciales y virtuales). Segundo, porque un conjunto de colectivos juveniles encuentra en las medidas de aislamiento una ventana de oportunidad. Frente al repliegue parcial de sectores que participan de forma activa y sostenida en la movilización callejera, los colectivos de «derecha» hacen un uso activo y fuertemente visible de las calles por medio de demandas que superponen las críticas a la gestión de la pandemia con las críticas al gobierno nacional. Sectores juveniles partidarios y religiosos disputan la representación política de las juventudes desde aquello que interpretan como parte de la «batalla cultural» - expresión que toman prestada del kirchnerismo - contra el «progresismo» y la izquierda. La idea de «ser joven» por medio de acciones que interpretan como parte de una «incorrección política» con impacto público y mediático produce adhesiones que, si bien no son mayoritarias, constituyen un aspecto emergente del contexto.

En este trabajo compartimos algunas reflexiones a partir de una primera levantada de datos empíricos con los que buscamos mostrar la centralidad que tiene el estudio de las formas de acción colectiva como clave de lectura de la coyuntura. El carácter descriptivo que adopta en algunas secciones se vincula con la reflexión sobre un contexto de pandemia en el que todavía nos encontramos al momento de escribir estas líneas. Esperamos que los datos y las ideas aporten a construir nuevas hipótesis para pensar las transformaciones a mediano y largo plazo que dejará este tiempo excepcional.

RECIBIDO: 29 DE JUNIO DE 2021 ACEPTADO: 3 DE SEPTIEMBRE DE 2021 


\section{BIBLIOGRAFÍA}

AgRIKOLIANSKY, É. (2001). Carrières militantes et vocation à la morale: les militants de la LDH dans les années 1980. Revue française de science politique, 51(1), 27-46.

Basualdo, V. y PelÁez, P. (2020). Procesos de conflictividad laboral en el marco de la pandemia del COVID-19 en Argentina (marzo-mayo 2020). Buenos Aires: FLACSO.

Chaves, M. (3 de junio de 2021). Hay una visión clasemediera y porteña en el debate sobre la presencialidad escolar, Contraeditorial. Recuperado de: https://contraeditorial.com/hay-una-vision-clasemediera-y-portena-enel-debate-sobre-la-presencialidad-escolar/

CIUFFOLINI, M. ET AL. (2020). La foto revelada. Informe sobre la situación social, conflictividad y medidas gubernamentales en la Córdoba de la pandemia. Córdoba: Edición de la Fundación El Llano/Cepsal.

COZACHCOW, A. (2020). Juventudes militantes en partidos en el gobierno. (Tesis doctoral). FSOC-UBA.

Della Porta, D. (2020). Movimientos sociales en tiempos de Covid-19: otro mundo es necesario. Open Democracy. Recuperado de: https:/www.opendemocracy.net/es/movimientos-sociales-en-tiemposde-covid-29-otro-mundo-es-necesario/

ELIZALDE, S. (2019). Hijas, hermanas, nietas: genealogías políticas en el activismo de género de las jóvenes. Revista Ensambles, (8), 86-93.

FEIXA, C. (2014). De la generación@ a la \#generación. La juventud en la era digital. Nómadas, 13, 75-91.

Filleule, O. (2020). Protest in a time of pandemic. Viena: Institut für die Wissenschaften vom Menschen.

- (2015). Propuestas para un análisis procesual del compromiso individual. Intersticios, Revista Sociológica de Pensamiento Crítico, 2(9), 197-212.

Filleule, O. y Tartarowsky, D. (2015). La manifestación: Cuando la acción colectiva toma las calles. Buenos Aires: Siglo Veintiuno Editores.

Galindo Ramírez, L. y Alves Oliveira, R. (2015). Movimientos juveniles y usos de las tecnologías digitales en América Latina. En H. CUBIDES, S. BORELli, R. UNDA LARA y M. VÁzQUEZ (eds.), Juventudes latinoamericanas. Prácticas socioculturales, políticas y políticas públicas (pp. 183-213). Buenos Aires: CLACSO. 
GEPOJU (2021). Ante la responsabilización de les jóvenes por la nueva ola de contagios. Recuperado de: http://gepojuiigg.sociales.uba.ar/ante-laresponsabilizacion-de-les-jovenes-por-la-nueva-ola-de-contagios/

Goldentul, A. y SAferstein, E. (2019). A la derecha de Macri... Los pibes para la reacción. Revista Espoiler, FSOC-UBA. http://espoiler.sociales.uba.ar/2019/07/07/a-la-derecha-de-macri-lospibes-para-la-reaccion/

HAIDAR, J. (2020). La configuración de proceso de trabajo en las plataformas de reparto en la Ciudad de Buenos Aires. Un abordaje multidimensional $y$ multi-método. (Informe de Coyuntura $\mathrm{N}^{\mathrm{o}} 11$ ). Instituto de Investigaciones Gino Germani.

LÓPEZ Mourelo, E. (2020). El trabajo en las plataformas digitales de reparto en Argentina: análisis y recomendaciones de política. OIT. Recuperado de: https://www.ilo.org/wcmsp5/groups/public/---americas/---ro-lima/--ilo-buenos_aires/documents/publication/wcms_759896.pdf

Melucci, A. (1988). Las teorías de los movimientos sociales. Estudios Políticos, 5(2).

Milan, S., Treré, E. y Masiero, S. (2021). COVID-19 from the margins: Pandemic invisibilities, policies and resistance in the datafied society. Ámsterdam: Institute of Network Cultures.

Morresi, S., SAfERstein, E. y Vicente, M. (2020). Ganar la calle. Repertorios, memorias y convergencias de las manifestaciones derechistas argentinas. Clepsidra. Revista Interdisciplinaria de Estudios sobre Memoria, 8(15), 134-151.

NataluCCI, A. ET AL. (2020). La protesta en cuarentena. Análisis de una base cuantitativa sobre protestas sociales en el marco del proyecto monitor laboral. Buenos Aires: CITRA.

Nava, A. y GrigerA, J. (2020). Pandemia y protesta social. Brooklyn, NY: Jacobin Press.

NúÑEZ, P. y GURVICH, D. (2021). «Volver o no volver»: la educación argentina en pandemia. Nueva Sociedad. https://nuso.org/articulo/escuelaargentina-presencialidad-educacion/

Pleyers, G. (2020). Los movimientos sociales y la batalla por el significado de la crisis del coronavirus. Pensamiento y Acción Interdisciplinaria, 6(1), 108-121.

PudAL, B. (2011). Los enfoques teóricos y metodológicos de la militancia. Revista de Sociología, 25, 17-35. Recuperado de: https://revistadesociologia.uchile.cl/index.php/RDS/article/view/27495/ 29168 
REguiLlo, R. (2017). Paisajes insurrectos: jóvenes, redes y revueltas en el otoño civilizatorio. Madrid: NED.

SAWICKI, F. y SimÉANT, J. (2009). Décloisonner la sociologie de l'engagement militant. Note critique sur quelques tendances récentes des travaux français. Sociologie du travail, 51.

Soto Pimentel, V., Gradin, A. y ReIRI, M. (2021). La conflictividad social en Argentina durante el 2020. Conflictividad social de Argentina en el año 2020. Un análisis de los hechos de protesta durante la pandemia del COVID-19. (Informe $\mathrm{N}^{\mathrm{o}} 20$ del Observatorio sobre Políticas Públicas y Reforma Estructural). FLACSO.

Stefanoni, P. (2021). ¿La rebeldía se volvió de derecha? Buenos Aires: Siglo XXI.

TAssinari, A., ChestA, R. E. y CINI, L. (2020). Labour conflictsover health and safety in the Italian Covid-19 crisis. Interface, 1(12).

UNICEF (2021). Encuesta de percepción y actitudes de la población. Impacto de la pandemia en la educación de niñas, niños y adolescentes durante 2020. Recuperado

de: https://www.unicef.org/argentina/media/10081/file/Impacto\%20COVID $\% 20-\% 203 \% 20$ Encuestas\%20Educacion.pdf

VÁzquez, M., Benedicto, J., Revillo Blanco, M., Martínez, M., Perez, O., Guaraná de Castro, E., Unda Lara, R., Llanos, D., TAguenca, J., A., Cozachcow, A., Gentile, F., Nessi, M., Mutuverría, M., González, R., Palenzuela, Y., Ponce, C., Pacheco, S., Castañeda, J., CÁrCAmo, F. y Vianna, C. (2021). Acciones colectivas juveniles durante la pandemia. Un estudio comparado en siete países. CLACSO.

VÁzquez, M. y Cozachcow, A. (2020). Demandas, sujetos y repertorios de movilización juvenil durante la pandemia. Apuntes para una reflexión sobre el presente. En E. Pérez (coord.), Diagnósticos y desafios de las infancias y las adolescencias en Argentina. Buenos Aires: Génera.

VÁzQUEZ, M. y VoMmaro, P. (2011). Activismo barrial de jóvenes organizados: algunas características de la militancia territorial en los barrios del Gran Buenos Aires. Revista Ánfora, (30).

Vicente, M. y SAFERSTEIn, E. (2020). De la «infectadura» a las plazas. Cuando las derechas toman las calles. Revista Anfibia. Recuperado de: http://revistaanfibia.com/ensayo/derechas-calles-infectadura/

VOMMARO, P. (2020). Juventudes, barrios populares y desigualdades en tiempos de pandemia. En M. DAMmerT-GuARDiA (Coord.), Múltiples miradas para renovar una agenda urbana en crisis. CLACSO. 
Ziegler, S. (2021). Educación: el Estado tiene que activar la sintonía. El Diario Ar. Recuperado de: https://www.eldiarioar.com/opinion/educacionactivar-sintonia-fina_129_7854180.html 
Anexo. Cuadro de ORganizaciones

\begin{tabular}{|c|c|}
\hline Nombre & Tipo de organización \\
\hline Juventud del Partido Demócrata, PBA & Partidaria \\
\hline Jóvenes por el Clima Argentina, CABA & Ambientalista \\
\hline $\begin{array}{l}\text { Juventudes Socialistas de Argentina, Provincia de Santa } \\
\text { Fe }\end{array}$ & Partidaria \\
\hline Greenpeace, Provincia de Mendoza & Ambientalista \\
\hline La Cámpora, CABA & Partidaria \\
\hline Rebelión o Extinción, PBA & Ambientalista \\
\hline Centro de Estudiantes Secundario, Provincia de Chaco & Estudiantil \\
\hline $\begin{array}{l}\text { Descendientes de Victoria, Rosario, Provincia de Santa } \\
\qquad \mathrm{Fe}\end{array}$ & Partidaria \\
\hline $\begin{array}{c}\text { Unión de Trabajadores Rurales Sin Tierra, Provincia de } \\
\text { Mendoza }\end{array}$ & Rural \\
\hline Unión de Trabajadores de la Tierra, Mar del Plata, PBA & Rural \\
\hline $\begin{array}{c}\text { Movimiento Nacional Campesino indígena, Provincia de } \\
\text { Santiago del Estero }\end{array}$ & Indígena \\
\hline $\begin{array}{c}\text { Centro de Estudiantes Colegio Nacional de Buenos } \\
\text { Aires, CABA }\end{array}$ & Estudiantil \\
\hline Jóvenes de Propuesta Republicana, CABA & Partidario \\
\hline Marcha por la vida, CABA & Antiderechos \\
\hline $\begin{array}{l}\text { Movimiento Trabajadores Excluidos (MTE-rama rural), } \\
\text { La Plata, PBA }\end{array}$ & Rural \\
\hline La Poderosa, CABA & Socio-territorial \\
\hline Juventud Sindical, PBA & Sindical \\
\hline Asociación Trabajadores del Estado (ATE), CABA & Sindical \\
\hline $\begin{array}{l}\text { Campaña Nacional por el derecho al aborto legal, seguro } \\
\text { y gratuito, CABA }\end{array}$ & $\begin{array}{c}\text { Feminismos y } \\
\text { disidencias sexuales }\end{array}$ \\
\hline Unión de Estudiantes Secundarios (UES), La Plata, PBA & Estudiantil \\
\hline $\begin{array}{c}\text { Juventud Federación Agraria Argentina, Río Cuarto, } \\
\text { Provincia de Córdoba }\end{array}$ & Rural \\
\hline Franja Morada, Provincia de Mendoza & Estudiantil \\
\hline Pibes Libertarios, CABA & Partidaria \\
\hline Zona, La Plata, PBA & Diversidades sexuales \\
\hline $\begin{array}{l}\text { Repartidores de Aplicaciones Unidos Argentina, Mar del } \\
\text { Plata, PBA }\end{array}$ & Sindical \\
\hline Frente Joven, Mar del Plata, PBA & Antiderechos \\
\hline $\begin{array}{l}\text { Juventud del Frente Popular Darío Santillán, Morón, } \\
\text { PBA }\end{array}$ & Socio-territorial \\
\hline Million Dollar Vegan, PBA & Ambientalista \\
\hline Juventud del Partido Justicialista*, Nacional & Partidaria \\
\hline Jóvenes Republicanos*, CABA & Partidaria \\
\hline
\end{tabular}

* Estas organizaciones fueron incluidas a partir de un trabajo de campo cualitativo desarrollado en Argentina y no integraron la muestra con la que se aplicó la encuesta «Acciones colectivas juveniles durante la pandemia» (Vázquez et al., 2021). 